\title{
IMPASSES DA NATUREZA HUMANA: SEMIFORMAÇÃO E ARTE COMO ANAMNESE DA HISTÓRIA
}

\author{
IMPASSES DE LA NATURALEZA HUMANA: SEMI-FORMACIÓN Y LA ARTE \\ COMO ANAMNESIS DE LA HISTORIA \\ IMPAIRMENTS OF HUMAN NATURE: SEMI-FORMATION AND THE ART AS \\ ANAMNESIS OF HISTORY \\ Cynthia Maria Jorge Viana \\ Universidade Federal de Goiás, Goiânia/GO, Brasil
}

Kety Valéria Simões Franciscatti

Universidade Federal de São João Del-Rei, São João Del-Rei/MG, Brasil

\begin{abstract}
RESUMO
Este artigo discorre sobre os aspectos da constituição do indivíduo e sobre o potencial epistemológico da arte como crítica às condições objetivas que fundamentam e obstam tal constituição. Para essa discussão teórica, tomam-se como base as contribuições de Theodor Adorno, em especial, no tocante às configurações de uma sociedade na qual impera a barbárie e às condições de possibilidade de formação cultural e de realização de uma vida justa e livre. Entende-se que o modo de racionalização da vida vem distanciando os homens de seus interesses racionais e sensíveis, pois quanto mais subjugados aos ditames da autoconservação, mais suscetíveis tornamse à dominação (segunda natureza). Como resistência, a arte, produção social que testemunha a potencialidade da história natural, configura-se como um procedimento racional não afirmativo do fracasso da cultura. Sua logicidade imanente guarda, na tensão forma e conteúdo, a capacidade dos homens de pensar para além das amarras objetivas e subjetivas.
\end{abstract}

Palavras-chave: indivíduo; cultura; arte; subjetividade; Theodor W. Adorno.

\section{RESUMEN}

Se abordam los aspectos de la constitución del individuo y el potencial epistemológico del arte como crítica a las condiciones objetivas que apoyan y dificultan tal constitución. Se toman como base los aportes de Theodor Adorno, en particular lo que se refiere a la configuración de una sociedad de barbarie y a las condiciones de formación cultural y de una vida justa y libre. Se entiende que la racionalización de la vida ha distanciado los hombres de sus intereses racionales y sensibles, pues sometido a los dictados de la propia conservación, se vuelven más susceptibles a la dominación (segunda naturaleza). Como resistencia, el arte, la producción social que demuestra el potencial de la historia natural, aparece como procedimiento racional no afirmativo del fracaso de la cultura. Su logicidad inmanente guarda, en la tensión forma y contenido, la capacidad del hombre para pensar más allá de los vínculos objetivos y subjetivos.

Palabras clave: individuo; cultura; arte; subjetividad; Theodor W. Adorno.

\begin{abstract}
This article discusses aspects of the individual's constitution and the epistemological potential of art as critique of underlying objective conditions that prevent such formation. To this discussion, the contributions of Theodor Adorno are taken as basis, in particular with regard to the settings of a society where barbarism prevails on the conditions of cultural formation and a fair and free life. It is understood that the way that life has been rationalized keeps pushing men away from their rational and sensitive interests, because the more they are subdued to the dictates of self-preservation, the more they become susceptible to domination (second nature). As resistance, art, a social production that bears witness the potential of natural history, sets up as a non-affirmative rational procedure of the failure of culture. Her inherent logicity, in the tension between form and content, conserves men's ability to think beyond the objective and subjective shackles.
\end{abstract}

Keywords: individual; culture; art; subjectivity; Theodor W. Adorno. 


\section{Introdução}

Com base nas elaborações do filósofo alemão Theodor W. Adorno no que tange aos impedimentos à constituição da subjetividade - privilegiando como recorte os textos que tratam do conceito de indivíduo, da semiformação, da ideia de história natural e de como a arte traz a anamnese de um subterrâneo sedimentado, uma segunda natureza -, este trabalho tece algumas considerações teóricas sobre as condições de possibilidades de formação do indivíduo e sobre a arte como conhecimento social e crítico de uma sociedade que obsta a sua realização. Ao apontar as condições objetivas e as suas contradições inerentes, o autor revela o quanto tais condições e também os homens encontram-se empobrecidos. Por outro lado, suas análises indicam que, como um lugar universal e histórico que resguarda elementos da singularidade, a arte se configura como refúgio do particular, o qual, dadas essas condições objetivas precárias, tem nela a expressão de sua dor. Ao objetivar-se como expressão do sofrimento e como mediação entre a estrutura social e a dinâmica das pulsões - que, por sua vez, também é determinada por essa estrutura -, a arte apresentase como um conhecimento diferenciado que se opõe à razão dominadora. Consubstanciada pela forma estética e pela expressão, a arte, cuja estrutura pressupõe uma lógica interna e uma organização precisa de materiais, permanece assim como negatividade.

\section{A constituição do indivíduo mediante as configurações de uma cultura opressiva}

A história da humanidade vem se configurando como a história da dominação. Essa é, talvez, uma das mais importantes considerações feitas pelos autores frankfurtianos a partir da análise que realizaram sobre a cultura, a sociedade e o indivíduo. Tal análise, de base essencialmente materialista, busca, na relação homem, natureza e história, indícios do que pode ser realizado pelo homem. É possível afirmar que os referidos autores atentaram para as condições objetivas concretas na intenção de pensar o que os homens constroem como sua subjetividade e de que maneira o fazem. Ao elegerem a cultura como uma das principais categorias de análise, seus esforços caminharam na tentativa de entender a contradição própria da cultura: a possibilidade de resguardar e realizar a vida e o componente de destruição presente nas realizações dessa mesma cultura, o que revela a suposta necessidade de dominação sobre si, sobre os outros e sobre a natureza e leva a uma organização social administrada.
Nesse sentido, torna-se importante salientar que, para Horkheimer e Adorno (1956/1973a), cultura e civilização são dimensões que se referem uma à outra, pois se a primeira diz respeito à capacidade dos homens de se relacionarem entre si e com as coisas e desenvolverem uma interioridade baseada nessa relação, a segunda é a base, no que se refere a recursos técnicos e materiais, para que a humanidade se sustente. A cultura pode ser entendida como natureza transformada; ela representa tudo o que o homem produz em sua relação com a natureza, ideia que exclui o entendimento de que haja um mecanismo imanente que confira à humanidade a capacidade de progredir. Ao discorrerem sobre cultura e civilização, Horkheimer e Adorno (1956/1973a) afirmam que “todas as épocas 'culturais' foram o que foram não por simples expressão de uma pura essência interna da humanidade, mas, outrossim, através do processo vital da sociedade e sua realidade nas coisas" (p. 96).

Entretanto, mesmo considerando essa mútua referência, a história da humanidade mostra uma separação entre tais dimensões: a cultura não vem se mostrando como um lugar de proteção, e a cisão entre a produção espiritual e o progresso material vem se constituindo um elemento de barbárie. Acerca dessa discussão, os autores são categóricos:

Sem dúvida, está ficando difícil separar o progresso técnico, não da civilização, mas da prostração na idiotia, em tal medida os homens estão sendo marginalizados do processo de produção de bens. A técnica é dona não só do corpo como do espírito dos homens e há uma cortina de mistificação tecnológica, tal como existe uma 'cortina monetária', de que a teoria econômica nos fala .... O que toda a cultura nada mais fez, até hoje, do que prometer, será realizado pela civilização quando esta for tão livre e ampla que não exista mais fome sobre a Terra. (Horkheimer \& Adorno, 1956/1973a, p. 99)

Uma sociedade civilizada e emancipada, cuja exigência fundamental seria a supressão da fome, desenvolver-se-ia como um complexo funcional no qual os homens, ligados uns aos outros e dependentes entre si, pudessem viver tendo garantidas as condições objetivas que resguardassem a sua sobrevivência. Porém, o progresso traz como marca a expropriação, uma das formas mais cruéis de dominação, e requer dos homens a reprodução de sacrifícios e atos embrutecidos.

A respeito desses elementos e da constituição humana, no texto "Sobre sujeito e objeto", Adorno (1969/1995) refere-se a essa relação a fim de destacar o movimento histórico do indivíduo, o qual é percebido como uma síntese de continuidade e ruptura. 
Se, com efeito, os homens, segundo tese de alguns biólogos modernos, nascem muito menos aparelhados que outros seres vivos, não podem conservar sua existência senão por meio de um trabalho rudimentar, isto é, associados; o 'principium individuationis' lhes é secundário, hipoteticamente, uma espécie de divisão de trabalho biológica. É inverossímil que, no princípio, tenha surgido, primeiramente, arquetipicamente, um homem individual qualquer. A crença nisso projeta miticamente para o passado, ou para o mundo das idéias, o 'principium individuationis' já plenamente constituído na história. A espécie talvez se tenha individuado por mutação para, logo, através da individuação, reproduzir-se em indivíduos, apoiandose no biologicamente singular. O homem é resultado, não Eidos; o conhecimento de Hegel e Marx funda as raízes no mais íntimo das chamadas questões da constituição. (Adorno, 1969/1995, p. 200)

A constituição da natureza humana pressupõe, como potencialidade histórica, o surgimento do indivíduo como mediação social autoconsciente. Isso significa dizer que o indivíduo é condição e resultado da cultura; é constituído, ao mesmo tempo, pela apropriação e negação da natureza: torna-se natureza transformada, forma-se entre ser e não ser natureza. Antes da possibilidade do surgimento do indivíduo, o que existe é uma indiferenciação entre homem e natureza, antes ainda, entre os hominídeos e a natureza. A constituição do Homo Sapiens em termos biológicos, sociais e históricos remete - em termos embrionários e com base na convivência, nas atividades e na comunicação - à mediação dessas dimensões no gênero humano, traços sociais e universais que antecedem e formam as condições para a constituição do particular (Horkheimer \& Adorno, 1956/1973b).

Esse entendimento também fica claro quando Adorno (1932/1991) busca conceituar natureza e história, na intenção de refletir sobre a possibilidade de que a cisão entre tais esferas seja superada (reconciliada), o que aparece no texto "La idea de historia natural". Em sua investigação filosófica, o autor conceitua o termo natureza por meio do conceito mítico, o qual é definido como algo que sustenta a história humana, algo que "aparece nela [na natureza] como Ser dado de antemão, disposto assim inexoravelmente, no que nela há de substancial" [tradução nossa] (p. 104). Por outro lado, o termo história designa o que, a partir dessa natureza, é capaz de produzir o diferente, "uma forma de conduta do ser humano ... que se caracteriza antes de tudo porque nela aparece o qualitativamente novo" [tradução nossa] (p. 104). O que é levado a cabo em sua investigação filosófica é a relação entre os dois conceitos, e, na tentativa de sobrepujar a dicotomia entre eles, Adorno indica os limites da posição filosófica dos idealistas, a qual parece dar margem à visão subjetivista do Ser e da História - algo que deveria ser superado -, além de se valer de conceitos de Benjamin e Lukács para trazer o conceito de história natural, o que remete diretamente à noção de indivíduo.

Desse modo, inspirado no trabalho históricofilosófico e estético de Benjamin e de Lukács - e resguardando as particularidades de cada um e as diferenças entre eles -, Adorno enfatiza que, para entender o conceito de história natural, é necessário ter em mente o caráter histórico da existência humana. Ela, como expressão e produção da história, indica que a história acontece para além de algo paralisado e acabado. A proposta do autor é de que a cisão entre natureza e história seja revelada e superada e, nesse entendimento, seja possível compreender o ser histórico como ser natural e, na inversão, o ser natural substanciado pela história. Nessa perspectiva, é possível dizer que a natureza se faz humana mediante a concepção de que o homem é historicamente natural e naturalmente histórico.

Se é que a questão da relação entre natureza e história deve ser colocada com seriedade, então só oferecerá um aspecto responsável quando consiga captar o $\mathrm{Ser}$ histórico como Ser natural em sua determinação histórica extrema, lá onde é maximamente histórico, ou quando consiga captar a natureza como ser histórico onde em aparência persiste em si mesmo até o mais profundo como natureza [tradução nossa]. (Adorno, 1932/1991, p. 117)

Do ponto de vista histórico-filosófico, natureza e história são conceitos que se relacionam intimamente: eles se fundamentam ao aparecer como significação um para o outro justamente no mais substancial que cada um resguarda - preservando o sentido de movimento que o conceito revela -, o que traz, necessariamente, elementos da proto-história, que só podem ser nomeados por meio da história como natureza transformada.

Tendo em consideração a antítese entre elementos proto-históricos originários, nomeados com base na história e no que foi possível fazer deles como algo inteiramente novo e originado, entre o que originou e o originado, ou entre o arcaico-mítico e o historicamente novo, se dá a noção de indivíduo. Este surge trazendo em si um paradoxo: por um lado, como antítese dialética, carrega a condição de se fazer como algo inteiramente novo, estabelecimento do diferenciado, entrelaçamento da natureza, da cultura e da sociedade, fruto do processo de formação cultural; por outro, também traz a possibilidade de, na tentativa de separação da natureza como algo a se fazer distinto desta, tentar dominá-la. É nesse retorno ao arcaico que 
há a constituição de um ser que, na separação de sua fundamentação como ser natural, acaba se distanciando da possibilidade de se individuar. Nessa tentativa de afastamento da natureza, o momento da reconciliação com a natureza e a superação da dependência com relação a ela é impedido, e a natureza não realizada como história (re)volta-se como vingança: retorna como segunda natureza, como suposta necessidade de dominação da natureza externa e interna. As marcas da dominação manifestam-se como expropriação que assolam tanto o que sustenta as condições sociais da existência humana (natureza não transformada), quanto a dinâmica pulsional - o que torna a renúncia erótica base do progresso da própria dominação.

Vale assinalar que o movimento histórico do conceito de indivíduo traz, em seu desdobramento, contradições que, na tradição filosófica, podem ser traduzidas pelas mônadas de Leibniz. Nessa concepção, mesmo resguardando algo de mediação, o indivíduo funcionaria segundo um princípio interno, responsável por dar origem a indivíduos concretos e fechados, sendo a sociedade o conjunto desses indivíduos. Dessa maneira, o indivíduo guarda a verdade dentro de si, estando sob a regência da mônada perfeita, da qual quanto mais se aproxima, mais conserva seu caráter de perfeição. Todavia, sua especificidade se perde e dá lugar à ideia de harmonia universal, justamente por pressupor algo distante da experiência e por dificultar o aparecimento do singular (Horkheimer \& Adorno, 1956/1973b).

$\mathrm{Na}$ discussão do conceito, os autores buscam compreender a relação indivíduo-sociedade para além do conceito de indivíduo como mônada ou como ser autossuficiente. Para os autores, o indivíduo se constitui a partir das relações sociais que estabelece na convivência com os demais membros da sociedade; sua singularidade vai se constituindo por meio dos processos de identificação e diferenciação, nos quais suas determinações históricas podem ser conhecidas. Como mediação social, o indivíduo reflete a relação natureza, cultura e homens, posto que fundamenta algo singular a partir da subjetivação da cultura.

O momento da relação com os outros remete ao conceito hegeliano de autoconsciência, que inspira Horkheimer e Adorno (1956/1973b) no entendimento do conceito de indivíduo. A autoconsciência superaria a noção de indivíduo como algo estritamente abstrato e fechado, ao trazer a ideia de que uma autoconsciência individual só se faz no contato com outra autoconsciência. É na relação com outra autoconsciência que o indivíduo surge como uma nova autoconsciência, da mesma maneira que a sociedade se configura como a abstração das diversas autoconsciências individuais (Crochík, 1999).
Essa ideia traz o entendimento de que o indivíduo se constitui na relação com seu semelhante, sendo esta uma necessidade vital no processo de formação da subjetividade. Tudo o que se afasta disso é aparência: nenhuma relação humana ocorre fora da esfera social. Nesse sentido, é falsa a ênfase dada ao indivíduo com um ser em si, tal como é ilusão o entendimento "de que cada homem chegou a ser o que é atuando, essencialmente, por si mesmo, por sua disposição natural e por sua psicologia" (Horkheimer \& Adorno, 1956/ 1973b, p. 53). Porém, cabe destacar que, mesmo falsa, a cisão entre indivíduo e sociedade também se apresenta como verdadeira, posto que ocorre na medida em que a história da cultura mostra um afastamento entre os interesses mais racionais dos indivíduos e os mecanismos que regem a sociedade: o indivíduo acaba por se converter em mônada, algo estritamente fechado e voltado para si, por desconhecer as determinações que o constituem, e a sociedade, um complexo funcional de indivíduos, começa a funcionar sem prezar por ele. Alienados em si mesmos, que é o mesmo que alienados de si, os indivíduos estão mortos: absorvidos por uma organização social opressiva e sob ditames ideológicos, os indivíduos supõem-se autossuficientes e acabam por não reconhecer a sociedade como produção da história, o que, nas condições estabelecidas, significa, também e fortemente, produção de barbárie. Alheados da própria constituição, a eles escapa a determinação de que "o mais individual é o mais universal" (Adorno, 1951/1993, p. 38).

Graças ao desenvolvimento tecnológico e econômico - cujo princípio é contrário ao estabelecimento de valores éticos e justos que sustentem a organização entre os homens - a sociedade se impõe como uma dimensão independente e autônoma.

Com a entronização do princípio de concorrência, a eliminação dos limites das ordens correlativas e o início da revolução técnica na Indústria, a sociedade burguesa desenvolveu um dinamismo social que obrigou o indivíduo econômico a lutar implacavelmente por seus interesses de lucro, sem se preocupar com o bem da coletividade. $\mathrm{O}$ impulso consciente para atuar nesse sentido foi favorecido pela ética protestante e o conceito burguês capitalista de dever. O ideal antifeudal da autonomia do indivíduo compreendia a autonomia da decisão política dos indivíduos; no contexto econômico, porém, transformou-se numa ideologia que exigia a manutenção da ordem vigente e o constante recrudescimento da capacidade de realização produtiva. Assim, para o indivíduo totalmente interiorizado, a realidade converte-se em aparência e a aparência em realidade. (Horkheimer \& Adorno, 1956/1973b, p. 55)

A sociedade, dimensão na qual as relações se estabelecem, desenrola-se alimentada por instâncias 
que poderiam levar à individuação, mas que se tornam empobrecidas quando cedem ao princípio da economia, cuja base é a dominação. Substancializado pela lei de mercado, o sistema social obsta a formação do indivíduo ao impedir que os homens se reconheçam neste sistema como mediação social e potencialidade do novo, do diferente.

Para Adorno (1959/1996), a dinâmica que envolve a sociedade revela o duplo caráter da cultura que, para além de ser condição para a formação e apropriação do existente, funciona, ao mesmo tempo, como instrumento de adaptação que alimenta um jogo sem sentido. Nesse jogo, os homens se tornam incapazes de um processo racional que negue esse existente. Assim, o prolongamento do sacrifício e o aprimoramento da tecnologia estão na base da cultura, posto que a formação cultural, processo de apropriação da cultura que traz a possibilidade de pensar um estado de homens livres e iguais, vem sendo rebaixada a uma existência mecanizada. Desse modo, seria mais correto falar em semiformação. Em uma sociedade que compartilha uma (ir)racionalidade que embota os sentidos e não realiza a vida - uma vida livre e justa -, a mediação entre a objetividade e a subjetividade, que é a legitimação do (des)encontro entre universal e particular, vem sendo rebaixada e apresenta sinais de uma adaptação irrestrita e irrefletida.

Até mesmo a religião, a ciência e a arte, quando operam de modo afirmativo - reproduzindo e ampliando um sistema social que não se realiza como um meio propício à formação cultural -, subjugam os homens, levando-os a um processo de coisificação e sofrimento (Horkheimer \& Adorno, 1956/1973b). Em tal inversão, de meios e fins, as instâncias de mediação se convertem em uma irracionalidade que, ao constituir os indivíduos, dificulta seu fortalecimento frente ao que atinge e impede um possível movimento de resistência contra o que não tem sentido. Isso tem como resultado instituições cuja racionalidade, além de violentar a capacidade do homem de pensar por si mesmo, formula falsas necessidades - quase sempre ligadas à hipóstase dos produtos da indústria e do mercado. Dessa maneira, o homem, imerso nessa condição, cria maneiras emburrecidas de se relacionar com os outros e, de modo embrutecido, torna-se frio e carente de contato. Pobre em experiência, acaba distanciando-se do que deveria ser seu principal objetivo: elaborar o medo na busca de formas qualificadas de gratificação; constituir-se como indivíduo em uma sociedade que possibilite condições de liberdade e felicidade, pois, assim, alcançaria "a sua existência própria, como indivíduo, numa sociedade justa e humana" (Horkheimer \& Adorno, 1956/1973b, p. 54).
Diante das contradições da sociedade e da cultura, percebe-se que o elemento que poderia levar os homens a se libertarem do jugo da sobrevivência é o esclarecimento. Horkheimer e Adorno (1947/1985) apontam, no prefácio da obra Dialética do esclarecimento, que, no mito, seria possível reconhecer vestígios do esclarecimento, e este se reverte em uma explicação mítica na medida em que assume sua racionalidade explicativa como verdade. Frente a uma natureza amedrontadora, o esclarecimento seria não um período histórico localizado, mas o processo de desencantamento do mundo, o qual liberta os homens do medo e os investe de poder. Em seus limites, quando se converte em mito, o esclarecimento perde sua capacidade de levar os homens ao conhecimento de suas determinações e acaba fundamentando uma formação falseada: atrelado ao princípio da dominação, o esclarecimento serve à regressão e ao contrário da formação de uma subjetividade capaz de se constituir mediante interesses racionais e sensíveis. Nesse processo, a constante luta pela autoconservação transforma o que haveria de mais progressivo - a possibilidade de entendimento por meio da razão em completa dominação da natureza. Revelar tais enredamentos é a tarefa sobre a qual esses autores se debruçaram, algo que se mostra - nesse texto e na obra de ambos - como um grito pela liberdade diante de um progressivo regresso que parece obstar a realização da humanidade na história. Ao mostrar os paradoxos do esclarecimento, da sociedade e da cultura frente aos impedimentos objetivos, o que se pede como desespero - como des-esperança de uma subjetividade danificada que, diante do desencantamento do mundo, emerge como possibilidade de enfrentamento da realidade opressiva - seria um olhar que se voltasse para o sujeito. Este teria sua formação resguardada na possibilidade de autorreflexão crítica sobre as condições objetivas e seus obstáculos.

A subjetividade, sendo constituída por meio da apropriação da cultura, traz a necessidade do fortalecimento dos laços de identificação e diferenciação entre os homens.

Nesse aspecto, é possível afirmar que a subjetividade é um projeto histórico indissociável da cultura. Tal dimensão é definida "pelo enfrentamento do que ameaça o homem, presente tanto nos desafios da natureza quanto nas regras de relacionamento humano criadas por ela [a cultura]" (Crochík, 1998, p. 71). Outra possibilidade de definição, em consonância com a apresentada, dar-se-ia no sentido mais pleno do termo, que envolve o entendimento de cultura como "cultivo da humanidade, como 'formação'. Vida civil, livre convivência na cidade, cidadania 
e, indo mais fundo na etimologia, lar, abrigo, local de repouso em paz" (Cohn, 2004, p. 82). O fato de considerar a natureza humana com base em uma relação mediatizada pela objetividade social e histórica pressupõe que os processos de interação social devam ser fundamentados na troca, na afetividade e no convívio com o outro - aspectos imanentes à mediação não opressiva e à comunicação diferenciada entre o universal e o particular (Adorno, 1969/1995).

Ao proporcionar o contato com o outro, a cultura deveria possibilitar uma relação formativa calcada no conhecimento de si e na percepção do outro como um ser diferenciado, e não somente como extensão do eu. Ao pressupor também a superação das amarras da cultura, a formação da subjetividade visualiza, no processo de diferenciação, a possibilidade de ir para além dos moldes da cultura. Assim, "a subjetividade implica a adaptação para poder ir além dela, o que significa que pela própria mediação da cultura o indivíduo pode pensá-la" (Crochík, 1998, p. 72). Contudo, além de pensá-la, é necessário indicar os limites da própria cultura, que, por vir impedindo a formação humana, acaba por ratificar o sofrimento e intensificar a barbárie. Quando a cultura não mais assegura uma vida justa aos homens, ela se transforma em algo tão ameaçador quanto a natureza da qual deveria protegêlos - de sua própria natureza, da natureza externa e das próprias relações de convivência entre os homens. Isso rebaixa o seu caráter de lugar particularmente capaz de possibilitar a autonomia (Crochík, 1998).

A racionalidade da sociedade atual requer reações rápidas, o que demonstra que os homens reproduzem sem reflexão o que recebem e, sem a mediação de uma cultura que deveria apontar para a formação, coisificam o objeto. As premissas são "nitidez na escolha do alvo, mobilidade e rapidez na decisão" (Cohn, 2004, p. 86), elementos indispensáveis à ação eficiente. A esperteza e a flexibilidade tornam-se habilidades imprescindíveis à esfera do trabalho, cuja base é mantida pela lógica do capital.

Ao fomentar o ajustamento do eu e impedir o processo de autorreflexão crítica, a cultura dificulta a dinâmica entre sujeito e objeto, o que leva o sujeito a se ver como algo independente dessa relação. Nesse movimento, a possibilidade de autonomia potencializase no seu contrário, e é a heteronomia que predomina em um mundo em que o sofrimento injustificado ainda não foi superado. Uma cultura que dissimula o sofrimento e reafirma o indivíduo como caricatura permanece na involução ao dizer de um sujeito que não existe, já que seus sentidos se encontram cindidos e não se ancoram em tal tipo de organização social. $\mathrm{O}$ particular se coisifica e, por não encontrar base no que o constitui, esquece que nem ele mesmo e muito menos o universal existem um sem o outro, pois "o particular só existe como determinado e, nesta medida, é universal; o universal só existe como determinação do particular, nesta medida, é particular. Ambos são e não são" (Adorno, 1969/1995, p. 199).

É nesse contexto ideológico que a arte, como produção da humanidade e testemunho do que esta ainda não realizou - a cultura como lugar de proteção e satisfação; uma sociedade justa e digna -, configura-se como um procedimento racional que opera diferentemente de uma racionalidade que se converteu em dominação: ela lembra à humanidade sua tarefa ainda não cumprida ao denunciar como a realidade vem se estabelecendo ao inverter meios em fins. O artista, como representante do sujeito social, traz, em sua participação subjetiva na arte, um modo contundente de denúncia da violência provocada pelas misérias da realidade.

\section{Anamnese do subterrâneo: a arte como crítica social}

Como fenômeno entre o enigmático e o realizável, a arte sempre esteve presente na história como uma atividade fundamental do ser humano. Mesmo antes da elaboração de uma teoria explícita sobre arte, desde a Pré-história, as expressões e manifestações artísticas representaram a possibilidade de transposição da realidade e a consecução da capacidade imaginativa. De acordo com Adorno (1970/1988), recorrer à arte para pensar a constituição da subjetividade, seus limites e condições de possibilidades, traz a indicação de que a esfera que a constitui, a cultura, vem se estabelecendo de modo opressivo, no qual a dinâmica pulsional tem, nela, poucas e cada vez mais escassas possibilidades de satisfação. A definição da arte como "antítese social da sociedade" (p. 19) traz a possibilidade de considerá-la como uma dimensão que se configura com base nos elementos da sociedade, esfera a que se opõe como um procedimento racional e crítico. A constituição da arte pressupõe também a passagem pela subjetividade, elemento importante do processo de criação artístico, que se inscreve nele como testemunho de uma mediação opressiva entre a estrutura da sociedade e a dinâmica pulsional - aspecto que caracteriza o desencontro entre o universal e o particular, que se manifesta como semiformação por se tratar de sedimentos da natureza humana, a protohistória.

Como contraponto a esse estado de coisas e parte de um procedimento objetivo, o artista, ao se retirar para imaginação e conseguir desvelar a opressão 
que recai nele e em todos, é tido como aquele que, supostamente privilegiado, é capaz de trazer à tona o sofrimento causado pelos impedimentos sociais. Sobre os artistas - mais especificamente sobre o sujeito poético -, Adorno (1957/2003) escreve:

Somente a pouquíssimos homens, devido às pressões da sobrevivência, foi dado apreender o universal no mergulho em si mesmos, ou foi permitido que se desenvolvessem como sujeitos autônomos, capazes de se expressar livremente. Os outros, contudo, aqueles que não apenas se encontram alienados, como se fossem objetos, diante do desconcertado sujeito poético, mas que também foram rebaixados literalmente à condição de objeto da história, têm tanto ou mais direito de tatear em busca da própria voz, na qual se enlaçam o sofrimento e o sonho. A afirmação desse direito inalienável tem sido uma constante, ainda que de maneira impura e mutilada, fragmentária e intermitente, a única possível para aqueles que têm o fardo para carregar. (pp. 76-77)

Diante das imposições sociais e de condições objetivas opressivas que impedem o estabelecimento da natureza histórica do homem, a arte, ao expressar as antinomias sociais, revela-se como negatividade, como anamnese do subterrâneo (Adorno, 1970/1988). Ante as cisões das faculdades humanas, provocadas por uma vida baseada na renúncia pulsional, cabe à fantasia/imaginação - capacidade de trazer à memória o que não se tem na experiência - conservar o que foi proscrito da vida não vivida e transcender o existente. Nesse sentido, a arte - e a fantasia/imaginação é um de seus elementos constituintes -, mesmo diante das marcas impostas pela sociedade, preserva-se como uma dimensão capaz de expressar as mazelas do todo, dada a sua própria organização.

Como mimese da realidade, a arte representa o real. Nela são refletidos aspectos do mundo de modo diferenciado, pois, como um procedimento racional capaz de trazer à tona o empírico e seus antagonismos, a arte se torna conhecimento da realidade justamente por não se fazer como mera cópia desta. A estrutura da arte retira elementos da objetividade para contornála e defrontá-la com os horrores ocasionados por essa mesma objetividade. A arte, assim concebida, representa, em Adorno (1970/1988), uma possibilidade de libertação da vida reificada experimentada pelos sujeitos, uma possibilidade de superar a compulsão à lógica da identidade e da mera mercadoria. Ao mostrar aos homens que eles podem ser mais do que coisa, a arte revela algo que deveria ser realizado na realidade e não vem se realizando: como possibilidade de experiência, mesmo enquanto experiência da não experiência, a arte tem a capacidade de proporcionar um instante de rompimento com a objetividade opressora, por oferecer ao sujeito, de modo mediado, o que lhe é negado na mera e massacrante sobrevivência.

Sem perder o caráter social que lhe é imanente, a arte como crítica à ideologia sublima o princípio da empiria graças a um princípio que lhe dá vida própria - a aparência. A obra de arte "aparenta-se com o mundo mediante o princípio que a ele a contrapõe e pelo qual o espírito modelou o próprio mundo" (Adorno, 1970/1988, p. 18). É sob o princípio da não identidade, diferente do princípio que rege a sociedade administrada, que a vida das obras de arte se dá de modo diferente da vida do sujeito que a cria. Sobre sua sobrevivência no tempo, pode-se afirmar que "as obras de arte possuem, no entanto, uma vida sui generis, que não se reduz simplesmente ao seu destino exterior" (p. 15). Independente da intenção do sujeito, a arte não tem como critério a categoria temporal, o que leva a pensar que uma obra não deva ser eliminada ou mantida porque foi realizada em outra época histórica, visto que "na sobrevivência das obras, porém, manifestam-se diferenças qualitativas que de nenhum modo coincidem com o grau de modernidade da sua época" (p. 55). O que as torna testemunho da humanidade - registro das agruras dessa humanidade - não é medido pelo avanço tecnológico alcançado pelo homem: seu momento de verdade está no fato de ser expressão de uma consciência negada e impedida de se fazer como crítica ao sofrimento.

A arte lembra à humanidade a natureza proscrita, que, temida e não realizada na história, precisa ser dominada. Nessa experiência, ela pode trazer o presente atualizado pela elaboração do passado e pela potencialidade de concretização de outro futuro (Resende, 2010). Nesse sentido, como possibilidade de acesso ao conhecimento e, também, ela própria como conhecimento, a arte diverge da ratio, pois ambas apresentam procedimentos diferentes. $\mathrm{Na}$ arte, há um procedimento racional que expõe a vida petrificada dos homens, algo reforçado pela (des)razão. Na argumentação de Adorno (1970/1988, 1951/1993), dada a sua substancialidade eminentemente social, a arte é produto de um trabalho social; nela há uma fúria pacienciosa que clama por justiça para a moção pulsional; há um trabalho contra o trabalho que aprisiona o homem na autoconservação (Franciscatti \& Viana, 2010).

Tal fúria se manifesta em uma concentração precisa, cujo objetivo é revelar o segredo dos objetos. Mesmo desconhecendo a motivação de tal fúria ou que esta não seja de todo clara/consciente, o artista, por meio da expressão e na forma, realiza uma obra que 
se torna um atalho para (re)conhecer o sofrimento e a violência objetiva socializada: diferente do crime, que, ao destruir os objetos, se apresenta como um atalho que reproduz a violência, a arte é negação determinada; como negação e resistência, ela expõe, mesmo sendo aparência, o corte no desejo, a subjetividade danificada (Horkheimer \& Adorno, 1947/1985).

Dessa perspectiva, a arte revela-se como contenção do golpe, uma vez que seu procedimento se dá na ausência de violência; não há destruição do objeto. Este é preservado e carrega consigo elementos da realidade, bem como a capacidade de ir para além deles, dada sua estrita relação com essa realidade e, especialmente, com o que não vem sendo realizado por ela. $\mathrm{Na}$ arte, o primado do objeto prevalece como elemento imprescindível para que ela apareça como testemunho de violência, posto que o objeto condensa, em suas articulações, as tensões e contradições do mundo externo. Por causar estremecimento diante da objetividade, "cada obra de arte é um instante; cada obra conseguida é um equilíbrio, uma pausa momentânea do processo, tal como ele se manifesta ao olhar atento" (Adorno, 1970/1988, p. 17). Na concepção adorniana, uma obra de arte pode suscitar, para além da fruição, um olhar atento para o horror e para a beleza escondidos na profundidade dos destroços do mundo.

Se, em conformidade com Adorno (1967/2001), afirma-se que a arte é crítica à sociedade, como ela se estrutura para que isso ocorra? Indícios para responder a essa questão, em Adorno, podem ser encontrados no texto "A arte é alegre", em que o autor traz a definição de arte séria. No referido texto, a partir de algumas contribuições de Schiller e em oposição a algumas de suas ideias, o autor menciona que a arte séria tem uma parte alegre - ressaltando que a alegria destacada nesse texto é diferente daquela proporcionada pela Indústria cultural, em que há uma falsidade implícita e um encantamento calculado -, algo de sua própria estrutura que lhe garante a participação no mundo como resistência. Entretanto, qual seria o critério que permite definir uma obra de arte como séria e alegre ao mesmo tempo? Para o autor, o alegre na arte não é o seu conteúdo, mas se refere ao seu procedimento, que, dialeticamente, mostra alegria na seriedade e seriedade ao encarar a realidade e denunciá-la. Desse modo, a arte é:

A priori, uma crítica da feroz seriedade que a realidade impõe sobre os seres humanos. Ao dar nome a esse estado de coisas, a arte acredita que está soltando as amarras. Eis sua alegria e também, sem dúvida, sua seriedade ao modificar a consciência existente. (Adorno, 1967/2001, p. 13)
Com base nessas considerações, é possível afirmar que a arte se realiza ao não resolver as contradições irreconciliáveis do todo, contradições estas que ela organiza em sua estrutura; preservaas e transforma-as em denúncia do que permanece sendo obstado à humanidade. Como tal processo não é externo, mas imanente ao seu procedimento, a profundidade da arte, como negação provida de conteúdo social, "mede-se pelo fato de poder ou não, pela reconciliação que suas leis formais trazem às contradições, destacar a real irreconciliação" (Adorno, 1967/2001, p. 13). Ao se defrontar com a real irreconciliação, a arte que se propõe séria tem como critério a expressão da tensão - ela não cede à ilusão de uma realidade supostamente reconciliada.

Desse modo, "como algo que escapa da realidade e, no entanto, nela está imersa, a arte vibra entre a seriedade e a alegria. É esta tensão que constitui a arte" (Adorno, 1967/ 2001, p. 13). $\mathrm{Na}$ tensão entre alegria e seriedade, há, no processo criativo, a possibilidade de vislumbrar vestígios que indiquem a saída do enredamento do mundo como dominação. Além disso, a participação do sujeito na arte pode levar a um voltar-se a si mesmo, não como um fechamento em si, mas como uma abertura; algo semelhante a um despertar para si e para o mundo. Nas palavras do autor, "é na alegria da arte que a subjetividade, de início, se conhece em seu próprio interior e se torna consciente. É pela alegria que ela se liberta do enredamento e retorna a si mesma" (Adorno, 1967/2001, p. 15).

Para além da participação subjetiva no processo de criação artístico, torna-se importante perceber a organização de alguns elementos que compõem a arte e permitem que ela tenha uma dinâmica peculiar, capaz de despertar a consciência e o entendimento em uma sociedade antagônica, de uma natureza histórica obstada. Como não se trata do conteúdo já que este possui um caráter enigmático, que foge à compreensão e à interpretação simples -, a obra organiza-se conforme uma lógica interna própria, que, sem imitar meramente o exterior, assemelha-se a ele sem que lhe seja da mesma essência. Sobre a lógica das obras de arte, Adorno (1970/1988) diz que, embora elas "não sejam conceptuais nem formulem juízos, são lógicas. Nada nelas seria enigmático, se a sua logicidade imanente não confluísse no pensamento discursivo, cujos critérios, no entanto, ela regularmente decepciona" (p. 157).

Ao tomar como base as considerações adornianas, é possível afirmar que a arte possui uma dupla dimensão: por um lado, se sua estrutura não apresentasse uma racionalidade possível de ser apreendida 
pelo pensamento, as obras seriam absurdas, não teriam sentido em si mesmas; por outro lado, se tudo em sua estrutura fosse traduzido em conceitos, elas não difeririam do pensamento discursivo e, assim, não teriam por que existir. Apesar de não serem traduzíveis em conceitos, as obras pressupõem uma racionalidade que, ao se aproximar do pensamento discursivo, é diferente deste e, por isso mesmo, consegue expressar o sofrimento da humanidade. Com base nesse entendimento, na preservação do seu conteúdo de verdade, a arte vai de encontro a tal pensamento por exercer, contundentemente, a tarefa que caberia também a ele, qual seja a de nomear o sofrimento, elemento que o pensamento discursivo por vezes desconhece e aprisiona em fechadas conceituações.

Nesse caráter unívoco, o pensamento discursivo torna-se estranho ao sofrimento e só com dificuldade consegue exprimi-lo, posto que isso implicaria, necessariamente, mostrar que sucumbiu a ele. Adorno (1970/1988) refere que, enredado na irracionalidade desse processo, "o sofrimento, reduzido ao seu conceito, permanece mudo e sem conseqüências" (p. 30), visto que a lógica do pensamento discursivo dificulta a expressão de dor e de fraqueza. Na tensão entre o que é exposto na arte e esse tipo de pensamento, o autor ressalta: "Enquanto que o conhecimento discursivo acede à realidade, mesmo nas suas irracionalidades, que, por sua vez, correspondem à lei de seu movimento, há nela [na arte] algo de inflexível em relação ao conhecimento racional" (p. 30). Isso indica que a arte, como conhecimento no qual se revela algo de inflexível, representa uma possibilidade de desvelamento do sofrimento objetivado, proscrito de certo modo do pensamento discursivo, uma vez que ela se apresenta como portadora de uma racionalidade própria que se opõe à irracionalidade, também engendrada pela realidade e caracterizada pelo aquiescer àquilo que traz sofrimento.

A racionalidade imanente à obra de arte é nomeada por Adorno (1970/1988) como "princípio de conseqüência lógica" (p. 157), que diz da configuração do todo, das suas contradições e de um impulso antimimético. Este, vindo do exterior, organiza-se em um interior que se configura como um processo racional, porém sem conceito e juízo. O impulso antimimético revela uma associação entre o externo e a estrutura da obra, além de trazer uma objetivação que adquire lógica própria - a obra vale por si; ela impõe seu próprio movimento -, a qual escapa à intenção subjetiva. Considerando esse movimento, pode-se dizer que as categorias da obra de arte não estão organizadas da mesma maneira que as categorias externas à obra. Categorias transcendentais - tempo e espaço, por exemplo - mostram-se de maneira diferente; a própria arte configura as suas categorias, tomando um sentido particular. Segundo Adorno (1970/1988),

as categorias formativas da arte não são, sem mais, qualitativamente diferentes das categorias externas, mas transpõem a sua qualidade para o medium qualitativamente diverso, apesar da sua modificação. Se essas formas são na existência externa as formas determinantes da dominação natural, são, por sua vez, dominadas na arte; lida-se com elas livremente. Através da dominação do dominante, a arte revê profundamente a dominação da natureza. A utilização dessas formas e da sua relação com os materiais torna evidente o seu caracter arbitrário. (p. 159)

$\mathrm{Na}$ arte, as categorias são influenciadas pelo exterior, mas, dentro da estrutura formal da obra, existem de outro modo e tornam-se outra coisa, ao comporem um procedimento cuja negatividade possui extrema racionalidade. As categorias da arte são geridas por si mesmas, algo conseguido em razão do caráter arbitrário da arte, que lhe permite, também, dominar a dominação da natureza - como contenção de ódio e preservação do objeto -, ao mesmo tempo que expõe tal dominação, tensionamento que faz com que a arte se contraponha à ratio dominante na medida exata que, ao trabalhar os sedimentos da segunda natureza (morta, não realizada), se configura como um produto social que resguarda a potencialidade de realização da natureza histórica. Diante do exposto, é possível afirmar que:

A lógica das obras de arte deriva da lógica formal, mas não se identifica com ela: eis o que revela no fato de as obras - e a arte aproxima-se assim do pensamento dialético - suspenderem a própria logicidade e poderem, no fim, fazer desta suspensão a sua idéia. (Adorno, 1970/1988, p. 159)

Ao estabelecer um tipo de acordo diferenciado com a realidade e, com isso, ter a capacidade de modificar e contornar essa mesma realidade, uma obra de arte - por meio de um processo dialético de elevar e suspender sua lógica interna - é capaz de falar sobre o mundo e de reconfigurar o mundo segundo uma lógica que não é a do mundo, mas diz muito deste e de seus impedimentos. Desse modo, na arte, para Adorno (1970/1988), a superação das condições sociais vigora como seu conteúdo mais verdadeiro: não há nada na arte que não remeta ao que na objetividade aparece como falso; não há nada que não diga que a condição social está rebaixada e irreconciliada com o que há de mais humano. As obras que, de alguma maneira, resistem vão de encontro a toda maquinaria da indústria e ao ritmo intenso do trabalho; elas trazem 
consigo a própria história, resguardam elementos de uma singularidade que supera a lógica do lucro, do equivalente (Adorno, 1951/1993). Conforme Matos (2003), "todas as obras que se consideram universais no campo da cultura são resultado de universos que, aos poucos, superando as leis do mundo comum e, sobretudo, a lógica do lucro, se foram consolidando" (p. 60).

Pensar a arte como negatividade traz o entendimento de que ela corporifica, em sua racionalidade interna, uma autonomia que, sendo relativa ao mundo empírico, "potencializa a arte como conhecimento crítico da sociedade" (Fabiano, 2003, p. 498). Adorno (1970/1988), ao sugerir que, na arte, "algo aspira objetivamente" (p. 30), afirma que esta testemunha o que o véu do mundo objetivo, administrado e irracional tenta ocultar: a logicidade da arte permite que o sofrimento dos homens diante das mutilações sociais seja desvelado. O que aspira objetividade na arte é a sua capacidade de, pela forma, tensionada ao contéudo, dizer da miséria do mundo.

Como um fenômeno histórico que trata e desvela sua própria sedimentação, a aparência na arte vai de encontro à imagem mítica da sociedade, que, por se reverter em mito, apresenta uma imagem social cifrada que coisifica a consciência. Assim, "a imagem, compreendida e aceita literalmente, é falsa consciência necessária. Os choques da arte dirigidos contra tal imagem desejariam, não em última instância, fazer estourar aquela falsidade" [tradução nossa] (Adorno, 1966/1986, p. 83). A falsidade do real é apresentada de outra forma: por remeter a conteúdos históricos e estar entre o que é negado e o que deveria ser realizado pela cultura, a aparência na arte é remetida à expressão, e o conteúdo expresso nas obras é algo que só pode aparecer pela aparência. O que é reivindicado na arte como aparência é a reconciliação e, nesse sentido, a arte pede pelo novo, pela realização do indivíduo na história. $\mathrm{Na}$ arte, o mais legítimo é o irrevogável pedido de que a situação de miséria em que a humanidade se encontra deixe de existir.

\section{Considerações finais: autorreflexão como esistência à sedimentação da história}

O retorno à história a fim de encontrar resquícios de como esta se configurou e, mais ainda, a busca pelos determinantes objetivos que constituem a subjetividade tornam-se importantes, pois apontam que os elementos de dominação da cultura ainda não foram superados. Isso oblitera a capacidade de resistência dos homens frente aos desafios que devem enfrentar por uma vida mais justa. Enquanto o que foi negado pela cultura não for superado na história, mesmo que a humanidade se aprimore no tocante à técnica, continuará produzindo homens cujas capacidades psíquicas, ao estarem cindidas, acabam mantendo os aspectos ideológicos de uma cultura rebaixada. Enquanto a razão que sustenta a organização da sociedade se mostrar incapaz de, razoavelmente, atender aos impulsos eróticos dos homens, a humanidade estará distante da superação das contradições entre a particularidade e a universalidade (Adorno, 1966/1986). A renúncia pulsional, como base do progresso da dominação, torna-se cada vez mais o fundamento de uma irracionalidade indiferente à razão e aos impulsos eróticos e às emoções. Contrária ao que deveria realizar, a cultura fundamenta o seu reverso e, na obstrução do pensamento, tanto a autorreflexão crítica fica impossibilitada quanto os sentidos ficam embotados diante do horror que paralisa a vida, tornando-a sedimento do que poderia ser (Adorno, 1951/1993).

A superação da ratio tecnológica se dá na superação do que não permite pensá-la, na compreensão dos aspectos ideológicos da cultura, a qual, como ideologia do existente, impede a consciência de criticar a falsa consciência em que se tem tornado. Se é no interior da cultura que emanam forças destruidoras, somente nela está a possibilidade de superação de tal estado; somente nela reside a possibilidade de constituição de indivíduos autônomos. Residiria na denúncia do existente como possibilidade de resistência e na eliminação de elementos de dominação a possibilidade de transcender a situação atual, na qual coexistem várias ideologias. O fato de os homens estarem adoecidos diz respeito, em grande parte, ao fracasso da cultura e à atuação dessas ideologias sobre um eu frágil e sobre os desejos, os quais não encontram na objetividade sua realização. Por estarem deformados de antemão e subjugados ao sempre idêntico, os homens se submetem conscientemente aos paradoxos e à miséria da sociedade.

Dentro do cativeiro em que se transformaram as condições objetivas, a arte, como uma dimensão universal e histórica, lembra à humanidade as possibilidades proscritas; reivindica a realização de uma vida justa e satisfatória, a realização do indivíduo histórico na cultura e na história. Na arte, a participação subjetiva, que não se coaduna com o que é nefasto, traz a possibilidade de o pensamento se voltar, sem violência, para a realidade opressiva e a possibilidade de sua modificação, apesar da experiência incessante de sofrimento. 


\section{Referências}

Adorno, T. W. (1986). Postscriptum. In H. Jensen (Org.), Teoria critica del sujeto: ensayos sobre psicoanálisis y materialismo histórico (H. Jensen, Trad., pp. 77-83). Buenos Aires: Siglo XXI. (Original publicado em 1966)

Adorno, T. W. (1988). Teoria Estética (A. Morão, Trad.). Lisboa: Edições 70. (Original publicado em 1970)

Adorno, T. W. (1991). La idea de historia natural. In T. W. Adorno, Actualidad de la filosofía ((J. L. A. Tamayo, Trad., pp. 103-134). Barcelona: Paidós. (Original de 1932, publicado em 1973)

Adorno, T. W. (1993). Minima moralia: reflexões a partir da vida danificada (L. E. Bicca, Trad.). São Paulo: Ática. (Original publicado em 1951)

Adorno, T. W. (1995). Sobre sujeito e objeto. In T. W. Adorno, Palavras e sinais (M. H. Ruschel, Trad., pp. 181-201). Petrópolis, RJ: Vozes. (Original publicado em 1969)

Adorno, T. W. (1996). Teoria da semicultura (N. Ramos-deOliveira, B. Pucci, \& C. B. M. de Abreu, Trads.). Educação \& Sociedade, 17(56), 388-411. (Obra original publicada em 1959).

Adorno, T. W. (2001). A arte é alegre? In N. Ramos-Oliveira, A. A. S. Zuin, \& B. Pucci (Orgs.), Teoria crítica, estética e educação (N. Ramos-de-Oliveira, Trad., pp. 19-25). Campinas, SP: Autores Associados (Piracicaba, SP); Editora UNIMEP. (Original publicado em 1967)

Adorno, T. W. (2003). Palestra sobre lírica e sociedade. In T. W. Adorno, Notas de Literatura I (J. Almeida, Trad., pp. 6589). São Paulo: Duas Cidades; Ed.34. (Original publicado em 1957)

Cohn, G. (2004). Indiferença, nova forma de barbárie. In A. Novaes (Org.), Civilização e barbárie (pp. 81-89). São Paulo: Companhia das Letras.

Crochík, J. L. (1998). Os desafios atuais do estudo da subjetividade na psicologia. Psicologia USP, 9(2), 69-85.

Crochík, J. L. (1999). Notas sobre a formação ética e política do psicólogo. Psicologia \& Sociedade, 11(1), 27-51.

Fabiano, L. H. (2003). Adorno, arte e educação: negócio da arte como negação. Educação \& Sociedade, 24(83), 495-505.

Franciscatti, K. V. S \& Viana, C. M. J. (2010). Talento e criação artística: notas sobre o trabalho contra o trabalho. In A. C. A. Rezende \& J. C. Chaves (Orgs.), Psicologia social: critica socialmente orientada (pp. 93-120). Goiânia: Ed. da PUC Goiás.

Horkheimer, M. \& Adorno, T. W. (1973a). Cultura e civilização. In M. Horkheimer \& T. W. Adorno (Orgs.), Temas básicos da sociologia (A. Cabral, Trad., $2^{\text {a }}$ ed., pp. 93-104). São Paulo: Cultrix. (Original publicado em 1956)

Horkheimer, M. \& Adorno, T. W. (1973b). Indivíduo. In M. Horkheimer \& T. W. Adorno (Orgs.), Temas básicos da sociologia (A. Cabral, Trad., $2^{\text {a }}$ ed., pp. 45-60). São Paulo: Cultrix. (Original publicado em 1956)
Horkheimer, M. \& Adorno, T. W. (1985). Dialética do esclarecimento: fragmentos filosóficos (G. A. Almeida, Trad.). Rio de Janeiro: Jorge Zahar. (Original publicado em 1947)

Matos, O. C. F. (2003). Ética e comunicação: o problema do visível. Inter-Ação: Revista da Faculdade de Educação, $U F G, 28(1), 51-66$.

Resende, A. C. A. (2010). Arte e conhecimento. In A. C. A. Resende \& J. C. Chaves (Orgs.), Psicologia social: critica socialmente orientada (pp. 77-92). Goiânia: Ed. da PUC Goiás.

\section{Agradecimento}

À Capes, pela concessão das bolsas de mestrado, doutorado e doutorado sanduíche. Bolsa Doutoramento Processo n. 7720130.

Submissão em: 01/04/2014

Revisão em: 31/07/2014

Aceite em: 12/11/2014

Cynthia Maria Jorge Viana é doutoranda do Programa de Pós-Graduação em Educação da Faculdade de Educação da Universidade Federal de Goiás (PPGE/FE/UFG). Possui mestrado em Psicologia (2010) pelo Programa de Mestrado em Psicologia da Universidade Federal de São João del-

Rei (PPGPSI/UFSJ), graduação em Psicologia [Formação de Psicólogo] pela Universidade Federal de São João del-Rei (2007) e Licenciatura em Psicologia (2006) pela mesma instituição. Realizou doutorado sanduíche (Capes/ PDSE/2013-2014) no Instituto de Filosofía do Centro de Ciencias Humanas e Sociales do Consejo Superior de Investigaciones Científicas (IFS/CCHS/CSIC), em Madri, Espanha. Endereço: Rua 235, s/n. Setor Leste Universitário. CEP 74605-050. Goiânia/GO, Brasil. E-mail: cynthiapsicol@gmail.com

Kety Valéria Simões Franciscatti é professora permanente do Programa de Pós-Graduação em Psicologia, pesquisadora do Laboratório de Pesquisa e Intervenção Psicossocial e professora Associada do Departamento de

Psicologia da Universidade Federal de São João Del-Rei (PPGPSI/LAPIP/DPSIC/UFSJ). Possui graduação em

Formação de Psicólogo e Licenciatura em Psicologia pela Universidade Metodista de Piracicaba, mestrado em Psicologia (Psicologia Social) pela Pontifícia Universidade

Católica de São Paulo (1998) e doutorado em Psicologia (Psicologia Social) pela Pontifícia Universidade Católica de São Paulo (2005). E-mail: kety.franciscatti@gmail.com 